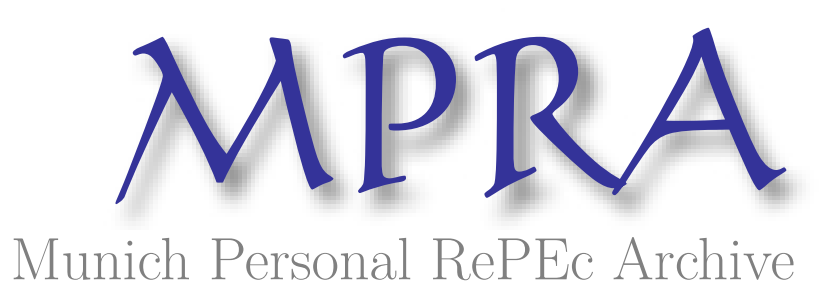

\title{
Spreading Academic Pay over Nine or Twelve Months: Economists Are Supposed to Know Better, but Do They Act Better?
}

Claar, Victor V and Diestl, Christine M and Poll, Ross D Hope College

2009

Online at https://mpra.ub.uni-muenchen.de/14273/

MPRA Paper No. 14273, posted 26 Mar 2009 04:08 UTC 


\title{
SPREADING ACADEMIC PAY OVER NINE OR TWELVE MONTHS: ECONOMISTS ARE SUPPOSED TO KNOW BETTER, BUT DO THEY ACT BETTER?*
}

\author{
Victor V. Claar \\ Department of Economics, \\ Management, \& \\ Accounting \\ Hope College \\ 41 Graves Place \\ P.O. Box 9000 \\ Holland, MI 49422-9000 \\ Voice (616) 392-7172 \\ vclaar@gmail.com
Christine M. Diestl
Department of Economics,
Management, \& Accounting
Hope College
41 Graves Place
P.O. Box 9000
Holland, MI 49422-9000
Voice (616) 395-7579
Fax (616) 395-7490
Ross D. Poll
Department of Economics,
Management, \& Accounting
Hope College
41 Graves Place
P.O. Box 9000
Holland, MI 49422-9000
Voice (616) 395-7579
Fax (616) 395-7490 \\ $\dagger$ Corresponding author
}

\begin{abstract}
Our paper empirically considers two general hypotheses related to the literature of behavioral economics. First, we test the null hypothesis that individuals behave, on average, in a manner more consistent with the rational expectations hypothesis than with the idea of self-control in the face of hyperbolic discounting in their saving decisions. Second, along a variety of dimensions, we examine whether individuals exhibit Herbert Simon's notion that the goal formation of individuals will differ depending upon their relative levels of experience and knowledge. Perhaps there are significant differences among groups in their saving decisions that depend upon their apparent levels of intelligence, education, and knowledge. Finally, using a variety of individual-specific control variables, we test for robustness of the results.
\end{abstract}

JEL classification: D11, D12, D91

Keywords: Consumer Economics, Empirical Analysis, Life Cycle Models and Saving

Date of this draft: 23 March 2009

DRAFT: Do not quote or cite without the permission of the corresponding author.

\footnotetext{
"The authors wish to thank Ronald Balvers, William Trumbull, John Lunn, Russell Rhine, and seminar participants in the economics departments at Western Michigan University and Hope College for helpful comments and suggestions. The authors are also grateful for feedback received during sessions at the meetings of the Southern Economic Association and the Midwest Economics Association. This research was partially underwritten by the Carl Frost Center for Social Science Research.
} 


\title{
SPREADING ACADEMIC PAY OVER NINE OR TWELVE MONTHS: ECONOMISTS ARE SUPPOSED TO KNOW BETTER, BUT DO THEY ACT BETTER?
}

\begin{abstract}
Our paper empirically considers two general hypotheses related to the literature of behavioral economics. First, we test the null hypothesis that individuals behave, on average, in a manner more consistent with the rational expectations hypothesis than with the idea of self-control in the face of hyperbolic discounting in their saving decisions. Second, along a variety of dimensions, we examine whether individuals exhibit Herbert Simon's notion that the goal formation of individuals will differ depending upon their relative levels of experience and knowledge. Perhaps there are significant differences among groups in their saving decisions that depend upon their apparent levels of intelligence, education, and knowledge. Finally, using a variety of individual-specific control variables, we test for robustness of the results.
\end{abstract}

JEL classification: D11, D12, D91

Keywords: Consumer Economics, Empirical Analysis, Life Cycle Models and Saving 


\section{SPREADING ACADEMIC PAY OVER NINE OR TWELVE MONTHS: ECONOMISTS ARE SUPPOSED TO KNOW BETTER, BUT DO THEY ACT BETTER?}

\section{Introduction}

Behavioral theorists augment neoclassical models in order to reconcile economic theory with observed phenomena. For example, Strotz (1956) models the timeinconsistency phenomenon. Herbert Simon pioneers the idea-summarized in Simon (1979) - that the goal formation of individuals will differ depending upon their relative levels of experience and knowledge, among other factors. More recently, Laibson (1997) finds that rational individuals with hyperbolic discounting of the future will opt for illiquid assets today in order to make it costly for their future selves to deviate from the saving pattern that appears optimal today. In a related paper, Angeletos, Laibson, Repetto, Tobacman, and Weinberg (2001) offer empirical evidence that an awareness of hyperbolic discounting may influence individuals' saving decisions in ways predicted by Laibson. Akerlof (2002) summarizes this literature.

Our paper empirically considers two related hypotheses. First, we test the null hypothesis that individuals behave in a manner more consistent with the rational expectations hypothesis than with the idea of self-control in the face of hyperbolic discounting. Second, we examine whether individuals' choices differ depending upon their relative levels of experience and knowledge. Finally, using a variety of individualspecific control variables, we test for robustness of the results. 


\section{Literature Review}

Under rational expectations, an individual would never overlook the time value of money in deciding when to receive income; in the absence of some other cost, sooner should always preferred to later. Nevertheless, university faculty with nine-month contracts often volunteer to spread their pay over the entire calendar year. In fact, Strotz (1956) himself states, "I select the option of having my . . salary dispersed to me on a twelve- rather than on a nine-month basis, although I could use the interest!” (p. 173).

Using data from their own academic institutions, Archibald (1994) and Graham and Isaac (2002) have explored this phenomenon. Archibald believes that there are two possible explanations. First, Archibald posits that the costs-explicit and implicit-in taking one's salary up front may be larger than they appear at first glance. For example, if a professor opts to take her salary over nine months rather than twelve, then she will need to engage in additional budgeting activities during the year. Also, frontloading one's pay may require more frequent bank trips or balance transfers in order to execute the budgeting plan. If these costs are not small, it may be perfectly rational for a professor to spread her salary over the calendar year.

Archibald's second possible explanation is that, even though faculty appreciate the need to take pay over the first nine months, they also know that they-like Strotzlack the willpower required to do so successfully. Using natural experiment evidence from the College of William and Mary, Archibald finds stronger support for the selfimposed constraint theory than for the notion that budgetary and transaction costs devour any possible interest earnings derived from frontloaded pay. 
In addition, Graham and Isaac (2002) admit the possibility of bounded rationality. That is, they follow Thaler (1994) and speculate that the optimization problem faced by college faculty may simply be too hard for even highly educated individuals to solve. As Hirshleifer (2001) points out, such circumstances occasion the need for some form of heuristic simplification.

Using evidence from a survey of 109 of their peers at American University, Graham and Isaac (2002) find that faculty behave in a manner much more consistent with behavioral economics than with the simple prediction of rational expectations. Graham and Isaac are careful to point out that insuring oneself today against how one may behave tomorrow does not constitute irrational behavior. In their words, "[t]he dispute concerns the constitution of rationality, not the fact of rationality" (p. 399).

\section{Data and Hypothesis Testing}

\section{A. Data}

Our hypothesis testing and analysis employs two unique data sets. The first consists of data received in response to requests mailed directly to public university payroll staff and Freedom of Information officers. We requested information regarding payment schedule choices for each university as a whole, as well as - in particular-its accounting, finance, and economics departments. The requests were sent to twelve public universities in the upper Midwest where economics, finance, and accounting faculty could be uniquely identified. Geographic proximity to our institution was a key factor in determining which schools received the requests. The total number of faculty included in the data set is 6,442 . 
Table 1 lists the schools that responded. Figure 1 groups economics, accounting, and finance faculty together and compares them to all other faculty members. The figure shows that economists, at $54.61 \%$, most frequently choose the nine-month payment option relative to the twelve-month. Finance faculty members were not far behind, with $51.46 \%$ choosing the nine-month option. In contrast, only $38.81 \%$ of accountants chose the nine-month payment option-considerably less than economics and finance faculty. About $38.69 \%$ of all other faculty members chose the nine-month option as opposed to $61.31 \%$ that chose the twelve-month option. The data are presented in Table 2.

\section{B. Hypothesis Testing}

\section{Hypothesis 1}

We test the following hypotheses in this section. First, we test the null hypothesis that university faculty uniformly make their academic pay distribution choice in accord with the prediction of rational expectations. That is, we test the null hypothesis that $\Pi_{A L L}$ $=1$, where $\Pi$ represents the proportion receiving their pay over nine months. Since the fraction of all faculty in the data set that select the nine-month option is only .3916 , we easily reject the null hypothesis in favor of a behavioral alternative.

\section{Hypothesis 2}

Second, we test whether individuals who presumably possess more knowledge or expertise know better what to do with their assets. We conduct this test across two dimensions. First, we consider whether there is heterogeneity among faculty related to their specific fields of academic expertise. In this case, we consider the null hypothesis that $\Pi_{\text {PVFIELDS }}=\Pi_{\text {OTHER }}$; that is, we test the null that the fraction of faculty paid over nine 
months in the fields that pay most attention the concept of present value-economics, accounting, and finance-is not different from the fraction of other faculty who do so. Calculation of the appropriate test statistic, distributed as a $z$, yields a value of 3.15. Hence, the null is easily rejected, giving evidence that individuals with more expertise may indeed know better what to do with their assets.

\section{Hypothesis 3}

Next, we conduct a related test for differences among the three disciplines. Our null hypothesis here is the joint null that $\Pi_{E C O N}=\Pi_{\text {FINANCE }}=\Pi_{A C C T I N G}$. Rejection of the null would imply significant discipline-specific differences among the three groups, perhaps suggesting the faculty in economics and finance understand better the time value of money than do their accounting counterparts. The appropriate test statistic of the joint null, distributed as a $\chi^{2}$ with two degrees of freedom, is 7.70 , which permits rejection of the joint null hypothesis at the $\alpha=0.05$ level of significance. The fraction of accounting faculty that receive their pay over 9 months $(.3881)$ is small enough compared to their finance (.5146) and economics (.5461) counterparts that we conclude that the differences among these fractions are not due to chance alone.

\section{Hypothesis 4}

Finally, we conduct an "IQ" test among institutions. That is, we consider whether faculty differ in their pay distribution choice across institutions of varying academic reputation. If, on average, more intelligent individuals are drawn to more prestigious academic institutions, then one could reasonably expect that a greater fraction of faculty at top institutions opt to receive their pay sooner rather than later. 
Using the stratification system and rankings given in U.S. News \& World Report - America's Best Colleges, we grouped the nine responding institutions into two categories: doctoral and master's. Among our responding institutions, six qualify as doctoral universities. Among these institutions, the fraction of faculty that receives pay in the first nine months is .4135 . The remaining three institutions are classified as master's universities. Here, the fraction of faculty that opts to receive pay in the first nine months is .3305 . Our null becomes $\Pi_{\text {DOCTORAL }}=\Pi_{\text {MASTER's. }}$ Calculation of the appropriate statistic, again distributed as a $z$, yields a value of 5.94. Hence we easily reject the null hypothesis of no difference between faculty at the two institution types.

\section{Preliminary Conclusions}

In this section of the paper we have conducted several empirical hypothesis tests surrounding two central ideas of behavioral economics. First, we examined whether faculty with nine-month academic contracts receive their pay over nine months, finding that they significantly opt to receive their pay over twelve rather than nine months.

Second, we probed whether there are significant differences among faculty depending upon proxies for their specific knowledge, expertise, and intelligence. Here our proxies were academic discipline and institutional type. In both cases we found significant differences.

Of course, our analysis is limited inasmuch as we offer little in the way of any control variables. Since we obtained our data via the Freedom of Information Act (FOIA), universities could not tell us more about specific individuals than what the institutions are obligated to supply as public information. In order to control for other 
variables, and to test the robustness of our results, we gathered an additional set of data using a web-based survey. We describe those data and our tests for robustness below.

\section{Data and Tests for Robustness}

While we have thus far been able to reject all null hypotheses in favor of behavioral alternatives, we have not controlled for any other factors that may influence a faculty member's pay frequency decision. Hence, in this section, we test the robustness of our results once we have controlled for other possible individual-specific factors that could influence a professor's choice.

We subsequently conducted a web-based survey of faculty in public universities in Michigan in order to obtain information regarding individual-specific factors related to our research question. Using e-mail, we contacted a randomly-chosen sample of faculty from nine universities. We selected these institutions because they are large enough that we were able to identify uniquely professors of accounting, economics, and finance.

We had previously telephoned human resource departments at these and other public universities in Michigan to determine whether their faculty indeed have the option to receive their pay over nine or twelve months. Three of the institutions we contactedMichigan State University, the University of Michigan at Ann Arbor, and Wayne State University—-stated that they did not offer the option.

The email message contained a link to the survey web page, depicted in Figure 2. The survey was sent to a total of 662 faculty members. There were 180 survey responses, giving a survey response rate of approximately 27 percent. Refer to Table 3 for a summary of the responses. Of those 180 responses, only 155 could be used for the data 
analysis because they either did not fully complete the survey or they had calendar-year contracts instead of academic-year contracts (e.g., department chairs).

The dependent variable, TWELVEMONTH ${ }_{t}$, indicates whether a faculty member chooses the nine- or twelve-month pay option. If she chooses the twelve-month pay option, the dependent variable is one; the variable equals zero otherwise. We estimate a total of three specifications of our logit regression model that takes the general form

$$
\text { TWELVEMONTH }=x \beta+e,
$$

where $x$ is a vector of individual-specific characteristics that may influence an individual's paycheck disbursement choice.

In all specifications of the model we included variables indicating both faculty rank and area of academic expertise. For faculty rank, we included three dummy variables: $A S S T_{t}, A S S O C_{t}$, and $P R O F_{t}$. Each takes a value of one if a faculty member holds the rank of assistant, associate, or full professor, respectively. Individuals who fall outside of all these categories may include lecturers and instructors.

For area of expertise, we again included three dummy variables: $A C C T_{t}, E C O N_{t}$, and FINANCE $E_{t}$. Each takes a value of one if a faculty member defines her primary area of expertise as accounting, economics, or finance, respectively. Individuals who fall outside of all these categories include those teaching in other disciplines.

In our first specification we also included all variables our survey would permit. These were all 0-1 dummies designed to capture factors beyond academic rank (presumably also related to age) and area of expertise that might influence an individual's pay frequency choice. $K N O W_{t}$ is a variable reflecting whether an individual is aware that her institution offers a choice concerning when she may receive her pay. This variable 
corresponds to question number five on the survey. A "Yes" response takes a value of one, and indicates that an individual is aware of the choice available to her; the variable equals zero otherwise.

$P R I M I N C_{t}$ equals one if a faculty member's academic pay constitutes her primary source of income, and equals zero otherwise. $M A R R Y_{t}$ equals one if a faculty member is married, and equals zero otherwise. $\operatorname{MARHOUSE}_{t}$ equals one if a faculty member is both married and the primary household income earner, and zero otherwise. $C H I L D_{t}$ equals one if a faculty member has children, and zero otherwise.

We expected the estimated coefficients of $A C C T_{t}, E C O N_{t}$, and $F I N A N C E_{t}$, to all bear a negative sign. We anticipated that the estimated coefficient of the $K N O W_{t}$ variable would bear a negative sign — perhaps suggesting that those who are aware of their options have probably considered them and, consequently, opted not to spread their pay over twelve months.

For the variables that indicate faculty rank, $A S S T_{t}, A S S O C_{t}, P R O F_{t}$, we were less certain what sign(s) to expect for their estimated coefficients. However, we were nevertheless able to speculate about the values of the coefficients relative to each other. Assuming that faculty rank is somewhat correlated with age, then-following Simonone might expect that age brings wisdom; that is, one might expect that $\beta_{A S S T}>\beta_{A S S O C}>$ $\beta_{P R O F}$, indicating that younger faculty are relatively more likely to spread their pay over twelve months than are their counterparts.

We expected signs of the estimated coefficients of PRIMINC,$\quad M A R R Y_{t}$, MARHOUSE, and CHILD $_{t}$ to be positive, since the opportunity costs for these 
individuals of not budgeting carefully could impact a larger number of individuals than in the case of one faculty member living alone with no dependents.

Our initial logistic regression results are presented in the first column of Table 4. The $A C C T_{t}, E C O N_{t}$, and IINANCE $_{t}$ variables all bore the expected sign, although only the $A C C T_{t}$ variable appeared to be significant. $K N O W_{t}$ also yielded the expected sign, but appeared to be insignificant. The estimated equation gave the expected relationship among the variables indicating faculty rank. Among $\operatorname{PRIMINC}_{t}, \operatorname{MARRY}_{t}, \operatorname{MARHOUSE}_{t}$, and $C H I L D_{t}$, all but the coefficient of MARHOUSE $E_{t}$ matched our expectations. The $C H I L D_{t}$ variable was significant at the $\alpha=0.05$ level.

The high significance of the overall regression, combined with the low levels of significance of several our variables, led us to suspect that the model may have been overspecified. After preliminary testing confirmed our suspicion, we respecified the model in the following way. First, we reduced our faculty rank variables to two: $A S S T_{t}$ (defined as before) and $\mathrm{SENIOR}_{t}$, a variable that equals one if a faculty member holds either the rank of associate or full professor. SENIOR $R_{t}$ equals zero otherwise. Our thinking was that senior faculty may be older, have tenure, and —as a result—face a different optimization problem than their junior counterparts.

Second, we also reduced our academic area variables to two. Since finance is a subfield of economics, we pooled ECON ${ }_{t}$ and FINANCE $_{t}$ to create the ECONFIN variable. ECONFIN ${ }_{t}$ takes a value of one if a faculty member considers her primary area of expertise to be either economics or finance, and equals zero otherwise. 
Finally, we dropped $P R I M I N C_{t}$, and MARHOUSE $E_{t}$, from the equation since there appeared to be a collinear relationship among $\operatorname{PRIMINC}_{t}, M A R R Y_{t}$, and MARHOUSE . $_{\text {. }}$ Our results appear in the second column of Table 4.

Our respecified model and results confirm our suspicion that the original model had been overspecified. Both of the faculty-rank variables appear significant at the $\alpha=$ 0.05 level or better. The revised equation also maintains the expected relationship among the faculty-rank variables. The academic subject area variables continue to bear the expected sign. The sign on the marriage variable has changed, but the significance of that variable in the regression equation appears quite low. The $C H I L D_{t}$ variable was again significant at the $\alpha=0.05$ level.

Lastly, we augment the regression equation to include $M A S T E R$ ' $S_{t}$, a dummy variable that equals one if a respondent is employed at a university classified as a master's university by U.S. News \& World Report. Estimated coefficients from the augmented equation appear in the last column of Table 4.

In this final version, the regression exhibits the greatest level of significance. Both of the faculty rank variables are again significant at the $\alpha=0.05$ level or better. The expected relationship among the rank variables is preserved, although their estimated coefficients are not significantly different from each other. Both of the academic subject variables bear the expected sign and appear significant at either the $\alpha=0.1$ or $\alpha=0.05$ levels. The $C H I L D_{t}$ variable is again significant at the $\alpha=0.05$ level in the expected direction. While insignificant, the estimated coefficients of both MASTER' $S_{t}$ and $\operatorname{MARRY}_{t}$ nevertheless bear the expected sign. 


\section{Conclusions}

Our paper considers empirically two key hypotheses of the literature of behavioral economics. First, we test the null hypothesis that individuals behave, on average, in a manner more consistent with the rational expectations hypothesis than with the idea of self-control in the face of hyperbolic discounting in their saving decisions. Second, we examine whether individuals exhibit Herbert Simon's notion that the goal formation of individuals will differ depending upon their relative levels of experience and knowledge.

Using data from public universities, we examine these hypotheses in light of the decisions made by university faculty concerning whether to (1) receive their academicyear pay in the first nine months or (2) spread their pay over the entire calendar year. Our evidence is more consistent with the behavioral literature than with rational expectations. Further, individual-specific factors such as academic field and faculty rank are significant predictors. In particular, professors in economics and finance are significantly more likely to receive their pay sooner. We also find that individuals with children are significantly more likely to receive their pay over twelve months.

Hirshleifer (2001) catalogs a variety of judgment and decision biases, including the status quo bias - the tendency for an individual to prefer the default option among alternatives. Hence, the current paper could be extended to control for the manner in which pay options are presented to faculty at each institution, or how cumbersome making a switch might be. Unfortunately, measuring accurately and consistently the difficulty of making a payroll change across so many different institutions may be extremely problematic. An additional line of research could consider to what extent there 
might be a wealth or income effect since accounting, finance, and economics faculty are among the highest income earners within academia.

\section{References}

Akerlof, George A. 2002. "Behavioral Macroeconomics and Macroeconomic Behavior.” American Economic Review 92: 411-33.

Angeletos, George-Marios, David Laibson, Andrea Repetto, Jeremy Tobacman, and Stephen Weinberg. 2001. "The Hyperbolic Consumption Model: Calibration, Simulation, and Empirical Evaluation." Journal of Economic Perspectives 15.3: 47-68.

Archibald, Robert B. 1994. "How Many Paychecks? An Example of a Self-Imposed Constraint." Economic Inquiry 32: 696-702.

Graham, Fred and Alan G. Isaac. 2002. "The Behavioral Life-Cycle Theory of Consumer Behavior: Survey Evidence." Journal of Economic Behavior \& Organization 48: 391-401.

Hirshleifer, David. 2001. "Investor Psychology and Asset Pricing." Journal of Finance 56: $1533-97$.

Laibson, David. 1997. “Golden Eggs and Hyperbolic Discounting.” Quarterly Journal of Economics 112: 443-77.

Simon, Herbert A. 1979. "Rational Decision Making in Business Organizations." American Economic Review 69: 493-513.

Strotz, R. H. 1956. "Myopia and Inconsistency in Dynamic Utility Maximization." Review of Economic Studies 23: 165-80.

Thaler, Richard H. 1994. "Psychology and Savings Policies." American Economic Review 84.2: 186-92. 
Table 1. Responding Institutions

\begin{tabular}{|c|}
\hline Indiana State University \\
\hline Iowa State University \\
\hline Central Michigan University \\
\hline Eastern Michigan University \\
\hline Ferris (MI) State University \\
\hline Grand Valley (MI) State University \\
\hline Western Michigan University \\
\hline Bowling Green (OH) State University \\
\hline Miami University of Ohio \\
\hline
\end{tabular}

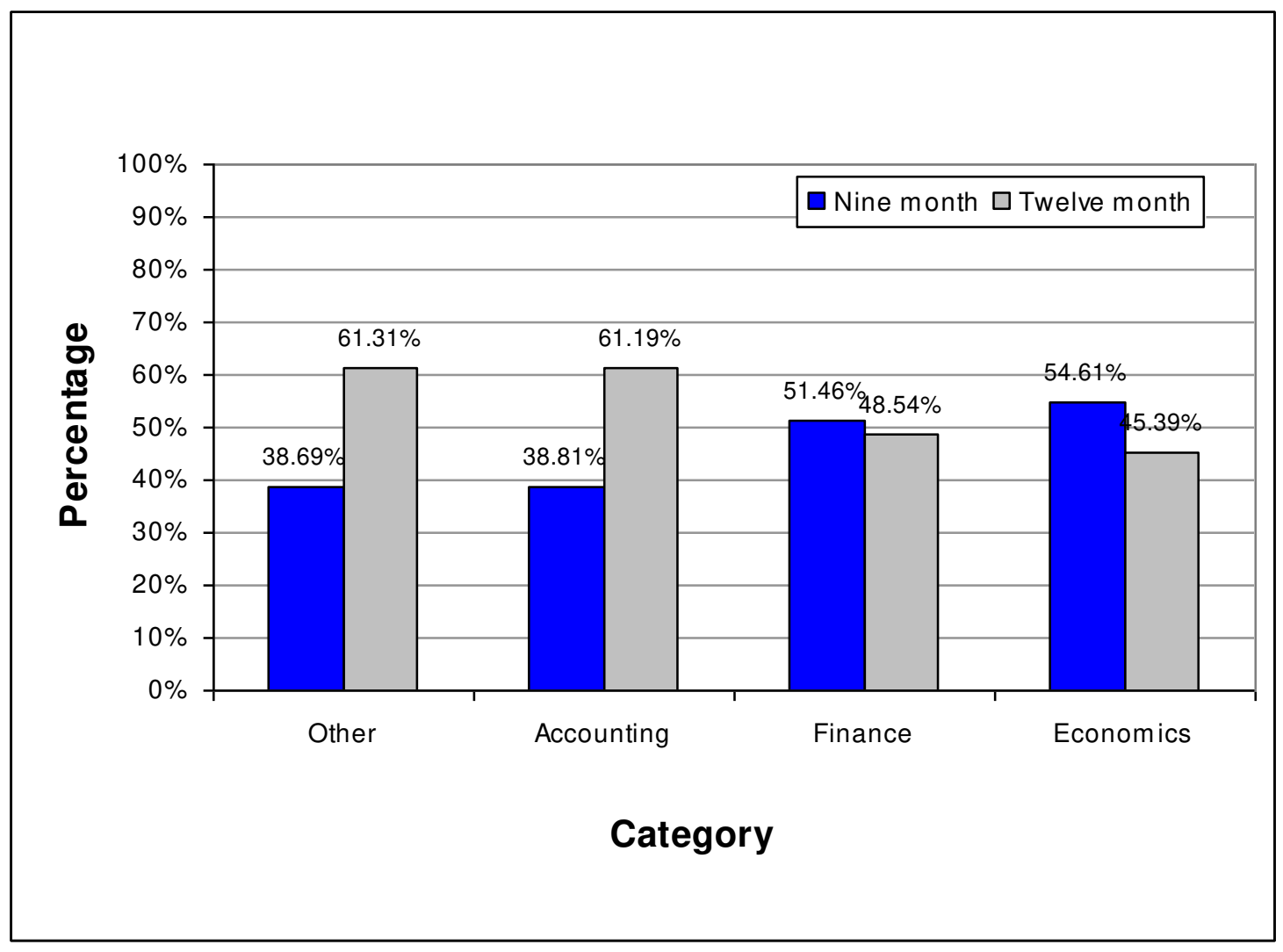

Figure 1. Distribution of Disbursement Choices Across Academic Department 


\begin{tabular}{|c|c|c|c|c|c|c|c|c|c|c|c|c|c|c|c|}
\hline \multirow[t]{2}{*}{ School } & \multicolumn{3}{|c|}{ University Total } & \multicolumn{3}{|c|}{ Economics Dept } & \multicolumn{3}{|c|}{ Accounting Dept } & \multicolumn{3}{|c|}{ Finance Dept } & \multicolumn{3}{|c|}{ All other Faculty } \\
\hline & Total & 9 mos. & 12 mos. & Total & 9 mos. & 12 mos. & Total & 9 mos. & 12 mos. & Total & 9 mos. & 12 mos. & Total & 9 mos. & $12 \mathrm{mos}$ \\
\hline Grand Valley State University & 546 & 159 & 387 & 8 & 6 & 2 & 13 & 3 & 10 & 8 & 0 & 8 & 517 & 150 & 367 \\
\hline Central Michigan University & 706 & 284 & 422 & 19 & 11 & 8 & 16 & 8 & 8 & 18 & 11 & 7 & 653 & 254 & 399 \\
\hline Western Michigan University & 761 & 161 & 600 & 17 & 3 & 14 & 14 & 5 & 9 & 17 & 9 & 8 & 713 & 144 & 569 \\
\hline lowa State University & 1178 & 744 & 434 & 37 & 23 & 14 & 16 & 3 & 13 & 9 & 2 & 7 & 1116 & 716 & 400 \\
\hline Eastern Michigan University & 667 & 246 & 421 & 11 & 7 & 4 & 15 & 8 & 7 & 20 & 15 & 5 & 621 & 216 & 405 \\
\hline Ferris State University & 421 & 135 & 286 & 5 & 3 & 2 & 9 & 4 & 5 & 3 & 3 & 0 & 404 & 125 & 279 \\
\hline Indiana State University & 526 & 148 & 378 & 9 & 5 & 4 & 7 & 1 & 6 & 4 & 1 & 3 & 506 & 141 & 365 \\
\hline Bowling Green State U. & 820 & 295 & 525 & 13 & 6 & 7 & 20 & 7 & 13 & 7 & 4 & 3 & 780 & 278 & 502 \\
\hline Miami University (Ohio) & 817 & 356 & 461 & 22 & 13 & 9 & 24 & 13 & 11 & 17 & 8 & 9 & 754 & 322 & 432 \\
\hline
\end{tabular}

\begin{tabular}{|c|c|c|c|c|c|c|c|c|c|c|c|c|c|c|c|}
\hline Totals & 6442 & 2528 & 3914 & 141 & 77 & 64 & 134 & 52 & 82 & 103 & 53 & 50 & 6064 & 2346 & 3718 \\
\hline ercentages & $100 \%$ & $39.24 \%$ & $60.76 \%$ & $100 \%$ & $54.61 \%$ & $45.39 \%$ & $100 \%$ & $38.81 \%$ & $61.19 \%$ & $100 \%$ & $51.46 \%$ & $48.54 \%$ & $100 \%$ & $38.69 \%$ & $61.31 \%$ \\
\hline
\end{tabular}

Table 2. Data Received from University Human Resource Departments in Fall 2001 
Figure 2. Survey Questionnaire

Please take a couple minutes to complete this short survey. All personal information will be kept confidential and any connection with your identity will be destroyed. Thank you for your cooperation.

Please enter the six-digit code from the email message. (For record-keeping purposes only. All responses are confidential.)

1. What is your current rank?

$$
\begin{aligned}
& 6 \text { Assistant Professor } \\
& 6 \text { Associate Professor } \\
& 6 \text { Professor } \\
& 6 \text { Other Full-Time } \\
& \text { Part-Time }
\end{aligned}
$$

2. How many years have you been at your current rank?

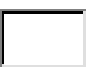

3. Which is your academic area of expertise?

$$
\begin{aligned}
& \odot \text { Accounting } \\
& \odot \text { Economics } \\
& \odot \text { Finance } \\
& \text { Other }
\end{aligned}
$$

If Other, please indicate your academic area of expertise

4. Is your teaching contract for the academic year ( 9 months) or the calendar year (12 months)?

$$
6 \text { Academic Year }
$$

5. Does your college/university provide faculty with academic-year contracts ( 9 months), the option to distribute their pay over either 9 or 12 months?

$$
\begin{gathered}
6 \text { Yes } \\
\text { No }
\end{gathered}
$$


6. If your teaching contract is for the academic year, do you receive your pay over 9 or 12 months?

$$
\text { 6 } 9 \text { months }
$$

7. Is your academic pay your primary source of personal income?

$$
6 \text { Yes }
$$

8. What is your current marital status?

$$
6 \text { Married }
$$

\begin{tabular}{|c|c|}
\hline Submit & Reset \\
\hline
\end{tabular}

9. If you are married, are you the primary income earner in the household?

$$
\begin{gathered}
\text { Yes } \\
\text { No }
\end{gathered}
$$

10. Do you have any children? 


\begin{tabular}{|c|c|c|c|c|c|c|c|c|c|c|c|c|c|c|c|}
\hline \multirow{2}{*}{ School } & \multicolumn{3}{|c|}{ University Total } & \multicolumn{3}{|c|}{ Economics Dept. } & \multicolumn{3}{|c|}{ Accounting Dept. } & \multicolumn{3}{|c|}{ Finance Dept. } & \multicolumn{3}{|c|}{ All Other Faculty } \\
\hline & Total & 9 mos. & 12 mos. & Total & 9 mos. & 12 mos. & Total & 9 mos. & 12 mos. & Total & 9 mos. & $12 \mathrm{mos}$. & Total & 9 mos. & $12 \mathrm{mos}$ \\
\hline Central Michigan University & 28 & 14 & 14 & 4 & 3 & 1 & 2 & 2 & 0 & 6 & 5 & 1 & 16 & 4 & 12 \\
\hline Eastern Michigan University & 16 & 6 & 10 & 1 & 1 & 0 & 4 & 2 & 2 & 1 & 1 & 0 & 10 & 2 & 8 \\
\hline Ferris State University & 10 & 3 & 7 & 0 & 0 & 0 & 0 & 0 & 0 & 0 & 0 & 0 & 10 & 3 & 7 \\
\hline Grand Valley State University & 31 & 11 & 19 & 4 & 3 & 1 & 3 & 0 & 3 & 3 & 0 & 3 & $21^{*}$ & 8 & 12 \\
\hline Lake Superior State University & 8 & 3 & 5 & 2 & 0 & 2 & 0 & 0 & 0 & 0 & 0 & 0 & 6 & 3 & 3 \\
\hline Michigan Technological University & 19 & 7 & 11 & $4^{*}$ & 0 & 3 & 1 & 1 & 0 & 1 & 0 & 1 & 13 & 6 & 7 \\
\hline Northern Michigan University & 4 & 2 & 2 & 3 & 2 & 1 & 0 & 0 & 0 & 0 & 0 & 0 & 1 & 0 & 1 \\
\hline Oakland University & 8 & 3 & 5 & 2 & 2 & 0 & 0 & 0 & 0 & 0 & 0 & 0 & 6 & 1 & 5 \\
\hline Saginaw Valley State University & 4 & 0 & 4 & 1 & 0 & 1 & 0 & 0 & 0 & 1 & 0 & 1 & 2 & 0 & 2 \\
\hline Western Michigan University & 40 & 9 & 27 & $9^{*}$ & 2 & 6 & $7^{\star}$ & 2 & 4 & 4 & 1 & 3 & $20^{\star *}$ & 4 & 14 \\
\hline Totals & 168 & 58 & 104 & 30 & 13 & 15 & 17 & 7 & 9 & 16 & 7 & 9 & 105 & 31 & 71 \\
\hline
\end{tabular}

* one respondent did not indicate which payment option they received, but were included in total

** two respondents did not indicate which payment option they received, but were included in total

Table 3. Survey Responses 
Table 4. Regression Results for the Logit Models

Dependent variable is TWELVEMONTH ${ }_{t}$.

\begin{tabular}{|c|c|c|c|}
\hline & \multicolumn{3}{|c|}{ Estimated Coefficients } \\
\hline Indep. Var. & (1) & (2) & (3) \\
\hline$A S S T_{t}$ & $\begin{array}{c}1.449 \\
(1.772)^{*}\end{array}$ & $\begin{array}{c}1.845 \\
(2.655)^{* * *}\end{array}$ & $\begin{array}{c}1.944 \\
(2.774)^{* * *}\end{array}$ \\
\hline$\overline{A S S O C_{t}}$ & $\begin{array}{c}1.239 \\
(1.502)\end{array}$ & & \\
\hline $\mathrm{PROF}_{t}$ & $\begin{array}{c}0.835 \\
(1.053) \\
\end{array}$ & & \\
\hline SENIOR $_{t}$ & & $\begin{array}{c}1.280 \\
(2.049)^{* * *}\end{array}$ & $\begin{array}{c}1.272 \\
(2.027)^{* *}\end{array}$ \\
\hline$A C C T_{t}$ & $\begin{array}{c}-1.002 \\
(-1.694)^{*}\end{array}$ & $\begin{array}{c}-0.826 \\
(-1.524)\end{array}$ & $\begin{array}{c}-0.932 \\
(-1.684)^{*}\end{array}$ \\
\hline$E C O N_{t}$ & $\begin{array}{c}-0.559 \\
(-0.992)\end{array}$ & & \\
\hline FINANCE $_{t}$ & $\begin{array}{c}-0.518 \\
(-0.739)\end{array}$ & & \\
\hline ECONFIN $_{t}$ & & $\begin{array}{c}-0.807 \\
(-1.904)^{*}\end{array}$ & $\begin{array}{c}-0.864 \\
(-1.994) * *\end{array}$ \\
\hline$K N O W_{t}$ & $\begin{array}{c}-0.571 \\
(-0.560)\end{array}$ & & \\
\hline PRIMINC $_{t}$ & $\begin{array}{c}0.329 \\
(0.439)\end{array}$ & & \\
\hline$M A R R Y_{t}$ & $\begin{array}{c}1.035 \\
(1.015)\end{array}$ & $\begin{array}{c}-0.232 \\
(-0.660)\end{array}$ & $\begin{array}{c}-0.468 \\
(-0.842)\end{array}$ \\
\hline MARHOUSE & $\begin{array}{c}-0.128 \\
(-0.244)\end{array}$ & & \\
\hline CHILD $_{t}$ & $\begin{array}{c}1.197 \\
(2.293)^{* * *}\end{array}$ & $\begin{array}{c}1.106 \\
(2.472)^{* *}\end{array}$ & $\begin{array}{c}1.014 \\
(2.215)^{* *}\end{array}$ \\
\hline MASTER'S $S_{t}$ & & & $\begin{array}{c}0.249 \\
(0.660)\end{array}$ \\
\hline constant & $\begin{array}{c}-1.675 \\
(-1.140)\end{array}$ & $\begin{array}{c}-0.889 \\
(-1.290)\end{array}$ & $\begin{array}{c}-0.734 \\
(-1.026)\end{array}$ \\
\hline & $\operatorname{LR} \chi_{(11)}^{2}=18.75$ & $\operatorname{LR} \chi^{2}{ }_{(6)}=19.06$ & $\operatorname{LR} \chi_{(7)}^{2}=19.43$ \\
\hline & Prob $>\chi^{2}=0.0657$ & Prob $>\chi^{2}=0.0041$ & Prob $>\chi^{2}=0.0069$ \\
\hline
\end{tabular}

$z$-statistics given in parentheses. ${ }^{*}, * *$, and ${ }^{* * *}$ indicate significance at the $\alpha=0.10$, 0.05 , and 0.01 levels, respectively. 